\title{
Motoneuron Intrinsic Properties, but Not Their Receptive Fields, Recover in Chronic Spinal Injury
}

\author{
Michael D. Johnson, ${ }^{1}$ Elma Kajtaz, ${ }^{1}$ Charlette M. Cain, ${ }^{2}$ and C.J. Heckman ${ }^{1,3,4}$ \\ ${ }^{1}$ Department of Physiology, ${ }^{2}$ Center for Comparative Medicine, ${ }^{3}$ Department of Physical Medicine and Rehabilitation, and ${ }^{4}$ Department of Physical Therapy \\ and Human Movement Sciences, Northwestern University Feinberg School of Medicine, Chicago, Illinois 60611
}

Proper movement execution relies on precise input processing by spinal motoneurons (MNs). Spinal MNs are activated by limb joint rotations. Typically, their movement-related receptive fields (MRRFs) are sharply focused and joint-specific. After acute spinal transection MRRFs become wide, but their manifestation is not apparent, as intrinsic excitability, primarily resulting from the loss of persistent inward currents (PICs), dramatically decreases. PICs undergo a remarkable recovery with time after injury. Here we investigate whether MRRFs undergo a recovery that parallels that of the PIC. Using the chronic spinal cat in acute terminal decerebrate preparations, we found that MRRFs remain expanded 1 month after spinal transaction, whereas PICs recovered to $>80 \%$ of their preinjury amplitudes. These recovered PICs substantially amplified the expanded inputs underlying the MRRFs. As a result, we show that single joint rotations lead to the activation of muscles across the entire limb. These results provide a potential mechanism for the propagation of spasms throughout the limb.

\section{Introduction}

Spinal injury not only disrupts the pathways that carry volitional motor commands from the cortex but can also severely impact descending neuromodulatory pathways from the brainstem (Heckman et al., 2003; Hultborn et al., 2004). Axons releasing serotonin and noradrenalin originate in the brainstem and diffusely innervate all segments and laminae of the spinal cord (Bjorklund, 1982). These neuromodulators act via G-proteincoupled second messenger systems to facilitate persistent inward currents (PICs) in the dendrites that interact with and amplify ionotropic synaptic inputs (Heckman et al., 2003, 2008; Hultborn et al., 2004). It has long been appreciated that neuron behavior is greatly impacted by neuromodulators. This impact is particularly relevant in the spinal cord where extrinsic neuromodulatory inputs are known to greatly influence motoneuron $(\mathrm{MN})$ intrinsic properties and transform their input-output processing through the activation of PICs (Bennett et al., 1998; Hamm et al., 2010), alteration of resting potentials, and reducing spike voltage thresholds (Rekling et al., 2000; Powers and Binder, 2001; Krawitz et al., 2001; Fedirchuk and Dai, 2004). Typically, this leads to an increase in gain and lowering of threshold in MN

Received June 19, 2013; revised 0ct. 18, 2013; accepted 0ct. 24, 2013.

Author contributions: M.D.J. and C.J.H. designed research; M.D.J. and C.M.C. performed research; M.D.J. and E.K. analyzed data; M.D.J. and C.J.H. wrote the paper.

This work was funded by National Institutes of Health Grants NS034382 and NS062200.

We thank Drs. Mathew R. Holmes, Christopher K. Thompson, and Jack Miller for critical surgical assistance and support; and Kathryn Mahoney CVT, RALAT, Carey Nichols CVT, LAT, and Danielle Stephens BS, CVT, RLATg for surgical assistance and postoperative care.

The authors declare no competing financial interests.

Correspondence should be addressed to Dr. Michael D. Johnson, Northwestern University Feinberg School of Medicine, 303 E Chicago Avenue, Department of Physiology, W5-295, Chicago, IL 60611. E-mail: m-johnson16@northwestern.edu.

DOI:10.1523/JNEUROSCI.2609-13.2013

Copyright $\odot 2013$ the authors $\quad 0270-6474 / 13 / 3318806-08 \$ 15.00 / 0$ outputs. These increases in intrinsic excitability are essential for normal motor behavior. In the absence of neuromodulation, spinal MNs are not able to produce the firing frequencies necessary for muscle activation to reach levels required to produce forces that sustain locomotor behaviors and maximum contractions (Binder et al., 2002; Heckman and Enoka, 2012).

Neuromodulation also has powerful effects on diverse populations of spinal interneurons, such as dorsal horn and intermediate zone interneurons (Jankowska et al., 2000; Maxwell et al., 2000; Dougherty et al., 2005), and commissural interneurons involved in coordinating left-right hindlimb activity (Hammar et al., 2004, 2007; Wang et al., 2011; Abbinanti and Harris-Warrick, 2012; Abbinanti et al., 2012). Recently, we have shown that acute spinal transection, which eliminates descending neuromodulatory input, severely disrupts the pattern of sensory inputs to spinal MNs, presumably via affecting premotor interneuronal circuits (Hyngstrom et al., 2008b). In the intact state, rotations of a single joint generate strong synaptic currents only in MNs innervating muscles at that joint. These movement-related receptive fields (MRRFs) are greatly broadened immediately after transection.

Previous studies using an in vitro preparation of the rodent sacral cord have established that MN PICs tend to recover within weeks after acute spinal transection (Bennett et al., 2001a; Murray et al., 2010). Unless $\mathrm{MN}$ receptive fields undergo a recovery to their focused preinjury state, MRRFs will remain broad; thus, an input to any part of the limb could evoke widespread excitation, potentially generating whole-limb (WL) spasms. Therefore, our first goal was to determine whether loss of this joint-specific somatotopy at the single-cell level after acute spinal injury persists as the chronic state begins to develop at 1 month after spinal transection. Our second goal was to determine the extent of PIC recovery and amplification of synaptic inputs in these MNs in this 
same time period. Our final goal was to compare cellular and system behaviors, to determine whether loss of descending neuromodulatory input affects the activation of other motor pools throughout the limb.

\section{Materials and Methods}

Ethical approval. All procedures were approved by the Northwestern University Institutional Animal Care and Use Committee. All animals were obtained from a designated breeding establishment for scientific research (Liberty Research). Animals were housed at Northwestern University Center for Comparative Medicine, which is an Association for Assessment and Accreditation of Laboratory Animal Care-accredited animal research program. The current dataset is compiled from 7 adult cats of either sex weighing between 2.5 and $5.0 \mathrm{~kg}$.

Survival surgery. All cats underwent a survival surgery where the spinal cord was completely transected at low thoracic levels $\sim 1$ month before the terminal experiment. The spinalization was performed under aseptic conditions in an operating room with sterilized equipment. Before surgery, cats were sedated (tiletamine-zolazepam, $3 \mathrm{mg} / \mathrm{kg}$, i.m.; glycopyrrolate, $0.01 \mathrm{mg} / \mathrm{kg}$, s.c.). Induction was performed with propofol (2-3 $\mathrm{mg} / \mathrm{kg}$, i.v.) or ketamine/diazepam $(4-5 \mathrm{mg} / \mathrm{kg}$, i.v.). Once anesthetized, cats were quickly intubated with a flexible endotracheal tube, and anesthesia was maintained by adjusting isoflurane concentration as needed $(1.5-3 \%)$. The fur overlying the back was removed, and the skin was aseptically prepped. A forelimb was shaved and an intravenous line was placed in a cephalic vein. The level of anesthesia was confirmed throughout the surgery by monitoring cardiac rate, respiratory rate, by applying pressure to the paw to detect limb withdrawal, and jaw tone and adjusted as needed. Body temperature was monitored using a rectal thermometer. Monitoring of the physiologic parameters was done on a continuous basis (i.e., cardiac and respiratory rates) and recorded every $15 \mathrm{~min}$. Cats received intravenous fluids (warmed lactated Ringer's solution or saline $+2.5 \%$ dextrose) at a rate of $5-10 \mathrm{ml} / \mathrm{kg} / \mathrm{h}$ throughout the surgery for cardiovascular support. Ophthalmic ointment was applied to the eyes.

A laminectomy was performed at T12-T13, and the spinal cord was completely transected with surgical scissors. Hemostatic material (Surgicel) was inserted at the transection site, and muscles and skin were sutured and closed in anatomic layers. A transdermal fentanyl patch (25 $\mu \mathrm{g} / \mathrm{h}$ ) was taped to the back of the animal $2-3 \mathrm{~cm}$ from the base of the tail. Before surgery and $\sim 7 \mathrm{~h}$ later, an analgesic (buprenorphine $0.01 \mathrm{mg} / \mathrm{kg}$ ) was administered subcutaneously and intramuscularly, respectively. The antibiotic (Baytril, $5 \mathrm{mg} / \mathrm{kg}$ s.c.) was given once a day for $5 \mathrm{~d}$ after spinalization to prevent urinary infection. The bladder was manually emptied 1 or 2 times each day up to the acute experiment. Padded flooring was provided in the cats' housing area to prevent pressure sores. The animals were monitored daily by experienced personnel and veterinary staff. The hindquarters of the cats were frequently cleaned by placing the lower half of the body in a warm soapy bath. Cats were not trained but allowed to freely explore their housing cage.

Terminal experiment. During the terminal experiments, cats were first placed in a clear plastic induction chamber and anesthetized with 1.5-3\% isoflurane in a 1:3 mixture of $\mathrm{O}_{2}$ and $\mathrm{NO}_{2}$. After $\sim 15 \mathrm{~min}$, cats were transferred to a surgical table and anesthesia was continued via a face mask. Once the animal was deeply anesthetized, a tracheostomy was performed and cats were intubated to deliver the anesthesia. The right common carotid artery and right jugular vein were cannulated to monitor blood pressure and for fluid administration, respectively. The level of anesthesia was confirmed by monitoring blood pressure, applying pressure to the paw to detect limb withdrawal, and by verifying the size and reactivity of the pupils and adjusted accordingly. Animals were then transferred to a stereotaxic frame. Keyhole incisions were made for inserting cuff electrodes to minimize disruption to the hindlimb skin. Cuff electrodes were applied to identified medial (MG) and lateral gastrocnemius (LG) nerves for antidromic stimulation of MNs. A dorsal vertebral spinal laminectomy was performed from S1 to L3 to expose the spinal cord for intracellular electrode insertion, and the cord was bathed in mineral oil. After a craniotomy, the cortex and all tissue rostral to the colliculi were removed (i.e., a precollicular decerebration). At this point, animals are considered to have complete lack of sentience and anesthesia was discontinued (Silverman et al., 2005). Paralysis was induced with Flaxedil (gallamine triethiodide) to effect. In three experiments, to measure EMG activity, the animals were not paralyzed. The cat's left hindpaw was attached to a six degree of freedom robotic arm (Staubli AG Robotics) and configured with the following joint angles: the interior angle of the hip, as measured from the vertebral column to the femur, was $115^{\circ}$; the interior angle of the knee, as measured from femur to the tibia, was $130^{\circ}$; and the ankle joint was at $90^{\circ}$. At the end of the experiment, the animals were given a lethal injection of potassium chloride $(2 \mathrm{mg} / \mathrm{kg})$ through the right jugular vein catheter, and a bilateral pneumothorax was performed (if not already done in efforts to aid intracellular recording stability).

$E M G$ recordings. Bipolar wire electrodes were inserted into the soleus (ankle extensor), semitendinosus (knee flexor/hip extensor), tibialis anterior (ankle flexor), and vastus lateralis (knee extensor) of the left hindlimb for EMG. EMG signals were amplified $(\times 1000)$ with a multichannel amplifier (AM Systems; model 3500), bandpass filtered (300$3000 \mathrm{~Hz}$ ), and sampled at 10,000 Hz. For receptive field analysis, EMG signals were rectified then smoothed ( $0.03 \mathrm{~s}$ time constant).

Intracellular recordings. Intracellular recordings of lumbar spinal MNs were performed using sharp electrodes ( $3-5 \mathrm{M} \Omega$ s) filled with $2 \mathrm{M}$ potassium citrate. Single-electrode discontinuous voltage-clamp (switching frequency $8-10 \mathrm{kHz}$ ) was applied using an Axoclamp 2a amplifier. Data with inadequate settling of electrode transients were rejected. To enhance the low-frequency gain in the negative feedback loop, an external gain circuit was used that allowed for gains of $100-300 \mathrm{nA} / \mathrm{mV}$ (Lee and Heckman, 2000).

Experimental protocols. For all voltage-clamp recordings, MG and LGS MNs were identified by antidromic stimulation of peripheral nerves. For experiments investigating the effects of PIC activation on MRRFs, the onset of the PIC was determined by applying a slow voltage ramp (6-8 $\mathrm{mV} / \mathrm{s}$ ), as in our previous studies (Lee and Heckman, 1996, 1998; Hyngstrom et al., 2008b). PIC onset voltage was identified at the point of zero slope in the resulting current-voltage relationship. The cell was then depolarized to PIC onset and the robotically imposed joint rotations applied.

The cat's hindlimb was attached to a 6 degrees of freedom robotic arm and adjusted to the start position: hip, knee, and ankle joint angles were $\sim 115^{\circ}, 130^{\circ}$, and $90^{\circ}$, respectively (Fig. 1, see Materials and Methods, terminal experiments). After an ankle extensor MN was successfully voltage-clamped, the robot passively flexed and extended the ankle $\left( \pm 15^{\circ}\right)$, the knee $\left( \pm 15^{\circ}\right)$, the hip $\left( \pm 10^{\circ}\right)$, and then the whole limb (WL, a movement comprised of a combination of the three individual joint rotations simultaneously). In some cases, a small amount of hyperpolarizing current was injected to hold the cell below firing threshold during the voltage-clamp recording while performing voltage ramps, as well has during the robotic joint rotations to ensure that the cells were subthresholded to PIC onset. For EMG experiments, the joint rotations were larger (ankle/knee $\pm 25^{\circ}$, hip $\pm 20^{\circ}$ ). These movements are well within each joint's physiological excursion range, and rotation-induced muscle length changes were determined using a realistic feline hindlimb model (Burkholder and Nichols, 2004). Previous experiments using joint markers, high-speed digital video (Adimec, 1000, $1 \mathrm{M}$ pixel, $50 \mathrm{fps}$ ), and custom analysis software established that the robot could manipulate joints separately with minimal influence $\left(<2^{\circ}\right.$ of joint angle change) at other joints (Hyngstrom et al., 2008b). The individual joint rotations and WL movements were repeated two times at a speed of $\sim 1 \mathrm{~Hz}$ with a delay of $0.5 \mathrm{~s}$ between repeats of each joint movement and $1 \mathrm{~s}$ between movements of different joints. The peaks and troughs $(\Delta \mathrm{PT})$ of the effective synaptic current $\left(\mathrm{I}_{\mathrm{N}}\right)$ at the soma generated by the movement-related synaptic input were recorded at resting membrane potential (zero current potential in voltage-clamp mode) to determine receptive field extent and at a depolarized potential corresponding to $5 \mathrm{mV}$ subthreshold to PIC onset to determine the presence of and magnitude of PIC-induced amplification.

Measurements. We followed the standard voltage-clamp convention, with inward (excitatory) currents defined by downward deflections from baseline and outward by upward deflections. We measured the peak-to- 


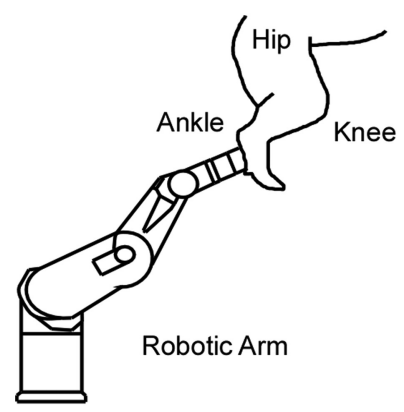

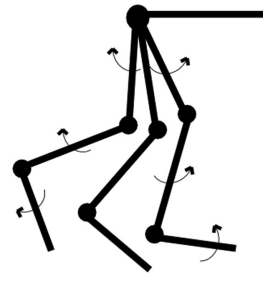

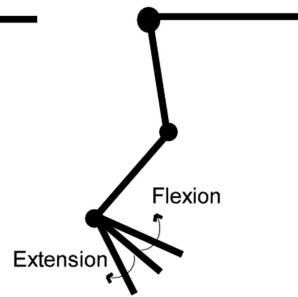

Whole Leg Movement

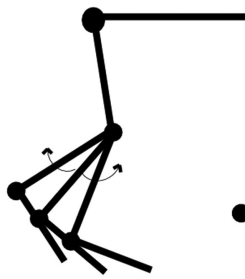

Knee

Flexion/Extension

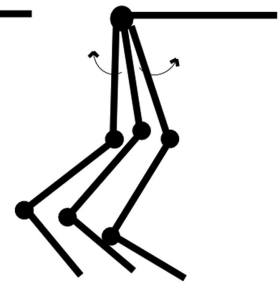

Hip

Extension/Flexion

Figure 1. Illustration of the experimental set-up, robot, and hindlimb configuration. The 6 degrees of freedom robotic arm was attached to the cat's hindlimb at the paw. The robot's control software allows it to precisely rotate the ankle, knee, and hip joints by defining the axis of rotation to correspond to each joint's center. This way, a joint is rotated in isolation without inducing movements at joints not intended to be moved.

trough amplitude of the current $(\Delta \mathrm{PT})$ generated by each joint rotation as well as its inhibitory component $(-\Delta \mathrm{PT}$, baseline to peak) and its excitatory component $(+\Delta \mathrm{PT}$, baseline to trough). The baseline current level was measured when no movements were imposed (note that our studies do not distinguish inhibition from disfaciliation and disinhibition from excitation) (Johnson et al., 2012). For the entirety of this paper, peak currents are outward and designated $-\Delta \mathrm{PT}$, and trough currents are inward and designated $+\Delta \mathrm{PT}$. PIC amplitudes were measured as the peak amplitude of the inward deflection of the current, measured during voltage ramps, in the leak subtracted current voltage function. For EMG measurements, response magnitudes were calculated as area under the curve of each rectified and smoothed response. Changes in EMG amplitude are expressed as the percentage change from the baseline EMG measured during a $3 \mathrm{~s}$ window before the onset of movement.

Statistical analysis. Data were processed and analyzed with IgorPro (Wavemetrics) Signal (Cambridge Electronic Design) and Microsoft Excel software, Student's $t$ test was used to evaluate significant differences.

\section{Results}

MN receptive fields remain broad 1 month after spinal injury We have previously shown that, in the intact mammalian spinal cord, MNs have narrow and selective receptive fields (Hyngstrom et al., 2008b). Ankle extensor MNs exhibit large depolarizing currents in response to ankle extension and substantial hyperpolarizing currents with ankle flexion but have much smaller responses to rotations at the knee and hip. After acute spinal transection, MN receptive fields widened dramatically as latent polysynaptic connections between stretch-sensitive afferents and MNs not normally active in the intact state became operative. A striking example was that the acute spinal transection allowed hip rotations to consistently evoke larger synaptic currents in ankle extensor MNs than ankle rotations (Hyngstrom et al., 2008b).

Data from the present study show that these aberrantly wide receptive fields persist in the chronically spinalized cat 1 month after transection. MN receptive fields were assessed from the change in peak-to-trough $(\Delta \mathrm{PT})$ current amplitudes for each robotically controlled movement during terminal experiments 1 month after complete spinal transection. Each cell's receptive field was defined by its $\Delta \mathrm{PT}$ responses to ankle, knee, and hip rotations and to the WL movement (Hyngstrom et al., 2008b). After penetrat- ing an ankle $\mathrm{MN}$ and performing basic voltage-clamp protocols to determine the presence of intrinsic electrical properties, the robot then imposed ankle, knee, hip, and WL rotations (see Materials and Methods). Effective synaptic currents were recorded at the soma during voltage-clamp, and the $\Delta \mathrm{PT}$ for each pair of movements was calculated. The cell in Figure 2 displays a wide receptive field and is a typical example of the response pattern seen in the cells in this study, showing an equally strong response to both hip and ankle rotations. On average, the receptive fields were wide for the population of ankle extensor MNs with equal and sometimes larger $+\Delta \mathrm{PT}$ and $-\Delta \mathrm{PT}$ values for hip rotations than for ankle rotations (Fig. 3, red traces indicate cells that had significantly larger ankle responses than hip responses, blue traces indicate significantly larger knee than hip responses, typical of the pattern seen in the uninjured spinal cord; Table 1). In the 14 cells in which responses to both hip and ankle rotations were recorded, $\Delta \mathrm{PT}$ of somatic currents evoked by hip rotations on average were not significantly different from $\Delta \mathrm{PT}$ current amplitudes evoked by ankle rotations (average $\Delta \mathrm{PT}$ for ankle rotations: $4.5 \mathrm{nA}$, average $\Delta \mathrm{PT}$ for hip rotations: $3.95 \mathrm{nA} ; 2$ tailed ttest: $p=0.26$ ). This was the case for both the depolarized and hyperpolarized condition (Table 2). Complete sets of measurements 


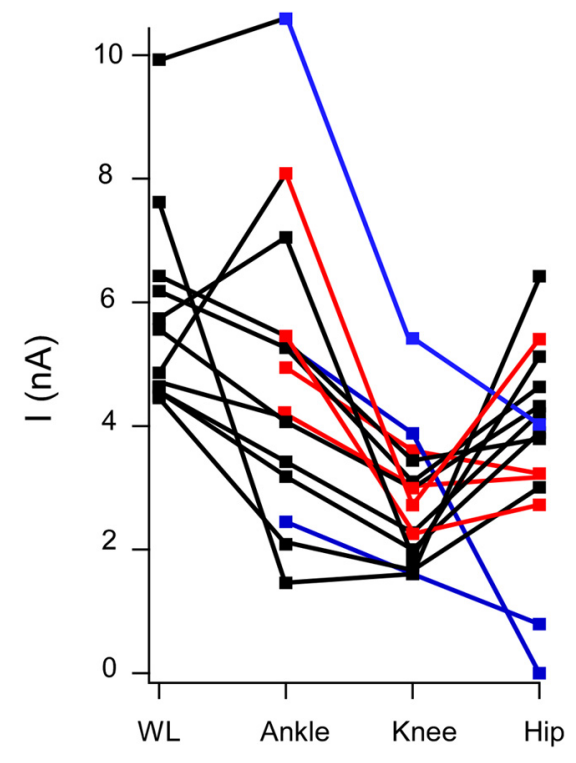

Figure 3. $\Delta \mathrm{PT}$ amplitudes for each ankle extensor $\mathrm{MN}$ in response to joint rotations and $\mathrm{WL}$ movements. In the uninjured spinal cord, ankle extensor MNs show the biggest responses to ankle rotations. Here, 1 month after spinal transection, in many cells hip rotation currents are as large as or larger than those evoked by ankle rotation. Red traces indicate cells that had significantly larger ankle responses than hip responses; blue traces indicate significantly larger knee than hip responses, typical of the pattern seen in the uninjured spinal cord.

Table 1. $-\Delta \mathrm{PT}$ and $+\Delta \mathrm{PT}$ currents measured in ankle extensor motoneurons at 1 month after spinal transection

\begin{tabular}{|c|c|c|c|c|}
\hline \multirow[b]{2}{*}{ Joint movement } & \multicolumn{2}{|l|}{ Depolarized } & \multicolumn{2}{|c|}{ Hyperpolarized } \\
\hline & $\begin{array}{l}-\Delta \mathrm{PT} \\
(n=11)\end{array}$ & $\begin{array}{l}+\Delta \mathrm{PT} \\
(n=11)\end{array}$ & $\begin{array}{l}-\Delta \mathrm{PT} \\
(n=11)\end{array}$ & $\begin{array}{l}+\Delta \mathrm{PT} \\
(n=11)\end{array}$ \\
\hline \multicolumn{5}{|l|}{ Ankle extension/flexion } \\
\hline Mean $\pm S D(n A)$ & $1.3 \pm 0.7$ & $3.5 \pm 1.5$ & $1 \pm 0.6$ & $2.8 \pm 1.5$ \\
\hline Minimum (nA) & 0.6 & 1.2 & 0.4 & 1 \\
\hline Maximum (nA) & 2.9 & 6.8 & 2.5 & 6.4 \\
\hline \multicolumn{5}{|l|}{ Knee flexion/extension } \\
\hline Mean $\pm S D(n A)$ & $1.1 \pm 0.9$ & $2.8 \pm 1.8$ & $0.7 \pm 0.8$ & $2 \pm 1.6$ \\
\hline Minimum (nA) & 0.0 & 1.2 & 0.0 & 0.9 \\
\hline Maximum (nA) & 3.4 & 6.9 & 2.9 & 6.5 \\
\hline \multicolumn{5}{|l|}{ Hip extension/flexion } \\
\hline Mean $\pm S D(n A)$ & $0.9 \pm 0.4$ & $2.8 \pm 1.4$ & $0.5 \pm 0.4$ & $2.2 \pm 1.6$ \\
\hline Minimum (nA) & 0.3 & 0.7 & 0.0 & 0.0 \\
\hline Maximum (nA) & 1 & 4.8 & 1.4 & 4.8 \\
\hline \multicolumn{5}{|l|}{ WL1/WL2 } \\
\hline Mean $\pm S D(n A)$ & $1.6 \pm 0.7$ & $5.2 \pm 1.5$ & $0.5 \pm 0.3$ & $2.4 \pm 1.5$ \\
\hline Minimum (nA) & 0.9 & 3.3 & 0.0 & 0.0 \\
\hline Maximum (nA) & 2.7 & 7.2 & 0.9 & 4.8 \\
\hline
\end{tabular}

comprising ankle, knee, hip, and WL movements, were obtained in 11 cells and their values comprise Tables 1 and 2, and Figure 3.

PICs amplify synaptic input at $\mathbf{1}$ month after spinal injury It has been shown that plateau potential-inducing persistent inward currents recover in MNs in the rat sacral cord within 1-5 months after spinal transection (Bennett et al., 2001b). These in vitro studies, however, lack an intact cord comparison for PIC amplitude. We thus measured the amplitudes of the PICs in our sample of chronic spinal cells and compared them with our database for the intact cord decerebrate preparation from our previous studies (Hyngstrom et al., 2007, 2008a; Johnson et al., 2012). As in these previous studies, we applied a depolarizing voltage ramp (40 mV/5 s) immediately before robotically imposed joint rotations to identify and measure PICs (see Materials
Table 2. $\Delta$ PT current values elicited by each joint rotation in the depolarized and hyperpolarized conditions

\begin{tabular}{lll}
\hline Joint movement & Depolarized: $\Delta \mathrm{PT}(n=11)$ & Hyperpolarized: $\Delta \mathrm{PT}(n=11)$ \\
\hline Ankle extension/flexion & & \\
Mean \pm SD (nA) & $4.4 \pm 1.3^{*}$ & $3.1 \pm 1.0^{* *}$ \\
Minimum (nA) & 1.6 & 1.4 \\
Maximum (nA) & 10.5 & 9.6 \\
Knee flexion/extension & & \\
Mean \pm SD (nA) & $3.9 \pm 2.6$ & $2.8 \pm 2.5$ \\
Minimum (nA) & 1.9 & 1.6 \\
Maximum (nA) & 5.5 & 4.5 \\
Hip extension/flexion & & \\
Mean \pm SD (nA) & $3.6 \pm 1.8^{*}$ & $2.8 \pm 1.7^{* *}$ \\
Minimum (nA) & 0 & 0.8 \\
Maximum (nA) & 6.3 & 5.4 \\
WL1/WL2 & & \\
Mean \pm SD (nA) & $6.6 \pm 1.6$ & $3.7 \pm 1.5$ \\
Minimum (nA) & 4.6 & 1.2 \\
Maximum (nA) & 9.9 & 5.7 \\
${ }^{*} p>0.26$. & \\
${ }^{*} p>0.27$. & &
\end{tabular}

and Methods). All cells in this study exhibited clear PICs (mean amplitude $12.1 \pm 7.1 \mathrm{nA}$ ), which peaked at a membrane potential range between -37 to $-33 \mathrm{mV}$. This represents a recovery of $84.3 \%$ of the PIC amplitudes seen in our previous studies of MN intrinsic properties in cats with intact spinal cords in which the hindlimb is kept in the same configuration (see Discussion).

In the intact cord, PICs strongly amplify the multimodal sensory currents generated by joint rotations (Hyngstrom et al., $2008 \mathrm{~b}$ ). This amplification, along with the coupling of excitation and inhibition in a push-pull arrangement (Johnson et al., 2012), increases the driving force for small IPSCs (Bui et al., 2008) and serves as means of increasing neuron input gain. To determine the degree of interaction between the recovered PICs in chronic injury and movement-related synaptic input, cells were given a depolarizing voltage step to bring the membrane potential to the PIC onset voltage. The robotic arm then imposed the same ankle, knee, hip, and WL rotations as for the hyperpolarized levels described above. Figure 4 shows the $\Delta \mathrm{PT}$ modulation of $\mathrm{I}_{\mathrm{N}}$ in an ankle extensor (LG) MN recorded in the hyperpolarized (bottom trace) and depolarized (top trace) condition. Figure 4 illustrates that the currents in this cell were larger for all joint rotations in the depolarized condition where PICs are present. This result was remarkably consistent. For all joint rotations in these cells, $\Delta \mathrm{PT}$ were significantly larger in the depolarized condition, where movement-related synaptic inputs are amplified by the PIC, than in the hyperpolarized condition (average percentage increase for $\Delta$ PT, depolarized vs hyperpolarized, ankle $41.9 \%$, knee $39.2 \%$, hip $28.6 \%$, whole leg $78.3 \%$, paired $t$ test, $p=0.001$ ) (Table 2; Fig. $5)$. This is in contrast with the situation after acute spinal transection where there is a profound loss of descending neuromodulation and PICs and hence no synaptic amplification (Hyngstrom et al., 2008b). Thus, the partially recovered PIC substantially amplifies all movement-induced synaptic currents, although much less than the amplification seen in the intact state (ankle 86.5\%, knee 95\%, hip 188\%, and WL 148\%) (Hyngstrom et al., 2008b), perhaps reflecting a tendency for muscle stretch to evoke simultaneous excitation and inhibition in the chronic spinal state (Frigon et al., 2011).

Disruptions at the single-cell level manifest at the system level Our previous study showed that the focused receptive fields of ankle extensor, as well as knee extensor MNs, became wide after 
acute spinal transection (Hyngstrom et al., 2008b). During the acute stage of spinal injury, the aberrant sensory inputs that clearly activate spinal MNs would nonetheless fail to produce muscle forces as MN excitability at this time is low. As PICs and excitability returns, these inputs could, in theory, bring MNs to firing threshold and cause unwanted muscle contractions. Our final set of experiments here were designed to address the question of whether this widening of receptive fields at the single-cell level would alter activation patterns of whole muscle pools and gross muscle activity once overall MN excitability starts to return in the weeks after spinal injury.

To test whether the clear disruption of receptive fields in single MNs impacts motor system output, we measured EMG activity of hindlimb muscles with actions at the hip, knee, and ankle (see Materials and Methods) and performed ankle, knee, and hip rotations with the robot as in the intracellular experiments. Figure 6 shows EMG activity from four muscles of the hindlimb to the individual joint rotations. Not only do muscles with actions at the ankle joint (soleus and tibialis anterior) show activity in response to ankle rotations, but so does the knee extensor vastus lateralis as does semitendinosus a hip extensor/knee flexor muscle. Similarly, knee and hip rotations not only produced activity in muscles acting at the knee and hip joint, but these rotations also activated ankle flexor and extensor muscles. All animals (3/3; Fig. 7) in the EMG experiments exhibited strong activity compared with intermovement intervals in multiple hindlimb muscles in response to isolated joint rotations (mean \pm SD: percentage change EMG in soleus: ankle $590 \pm 306 \%$, knee $490 \pm 120 \%$, hip $495 \pm 97 \%$; semitendinosus: ankle $570 \pm 240 \%$, knee $400 \pm 173 \%$, hip $480 \pm 120 \%$; tibialis anterior: ankle $495 \pm 145 \%$, knee $515 \pm$ $250 \%$, hip $580 \pm 80 \%$; vastus lateralis: ankle $560 \pm 260 \%$, knee $390 \pm 226 \%$, hip $170 \pm 81 \%$ ). This result is in marked contrast to the intact cord state, where stretch of the triceps surae generates strong EMG in these ankle extensors but not in hip or knee muscles (Frigon et al., 2011). This demonstrates that, in the chronic stages of spinal injury, individual joint rotations activate sensory pathways that span multiple spinal segments and reveal wide sensory receptive fields in many motor pools.

\section{Discussion}

Here we demonstrate that, 1 month after spinal transaction, MN receptive fields remain wide and movements of joints not associated with the motor units function cause neuronal activation. We also show, consistent with work in the rat (Murray et al., 2010; Rank et al., 2011), that PICs undergo a dramatic recovery. This previous work by Bennett et al., (2001b) however, relied on an in vitro preparation, which does not provide a reference for normal PIC amplitude in the intact cord state. Our in vivo preparation provides this comparison and shows that, even within the relatively short period of $30 \mathrm{~d}$, PICs recover to be nearly as large as in the intact state. These recovered PICs serve to amplify movement-related synaptic inputs. Finally, the data presented here suggest that the currents measured at the cellular level translate to behaviors at the system output level, as evidenced by the

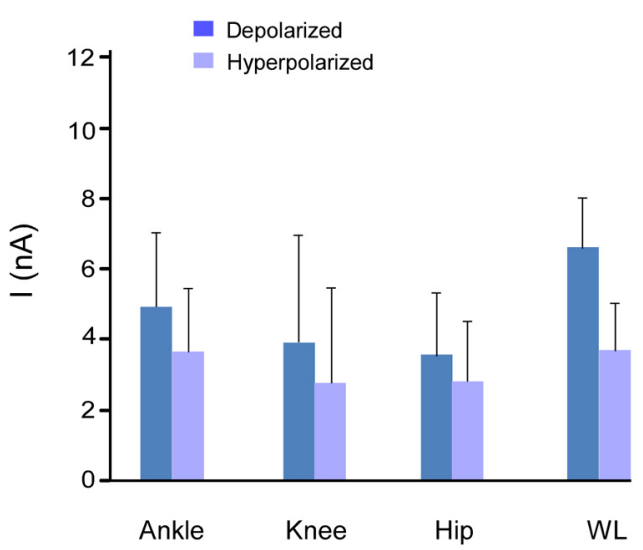

Figure 5. Average $\Delta \mathrm{PT}$ amplitudes for all ankle extensor MNs in response to joint and WL movements in the depolarized and hyperpolarized conditions. For all movements, $\Delta$ PT amplitudes were greater in the depolarized condition (top), where synaptic inputs interact with persistent inward currents, compared with the hyperpolarized condition (bottom).

increase in muscle activation patterns in response to joint rotations. These findings together offer a mechanistic explanation for the spread of spastic behavior throughout the entire limb. As MN PICs and excitability reemerge in the weeks after spinal injury, movement-related signals, normally narrowly focused by interneuronal circuitry, diffuse broadly to other $\mathrm{MN}$ pools resulting in unintended muscle contractions.

\section{Altered sensory processing and SCI}

Spasticity may manifest itself, not only by altering the response to stretch in the homonymous muscle but also by the emergence of unintended activation of other muscles. During the recovery process in the month after complete spinal injury, polysynaptic reflex patterns not present before injury become activated by muscle stretch (Frigon et al., 2011). Windup, the progressive response potentiation after repeated identical inputs (Mendell, 1966), has 
Sol

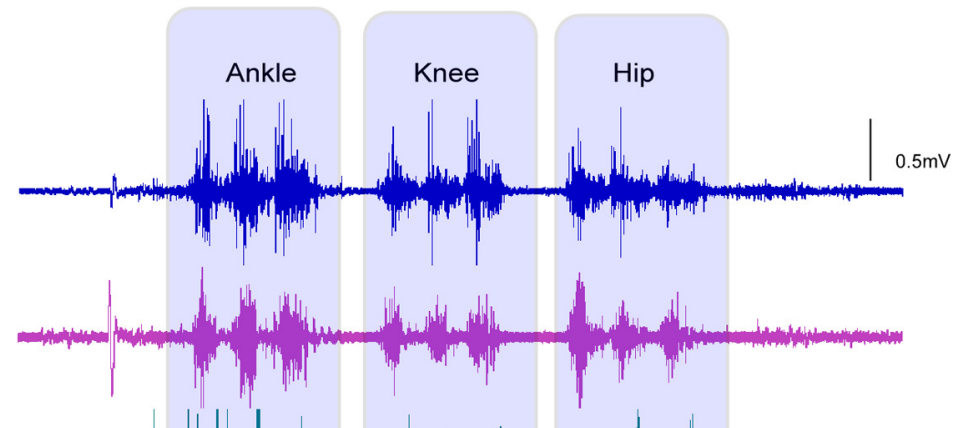

TA

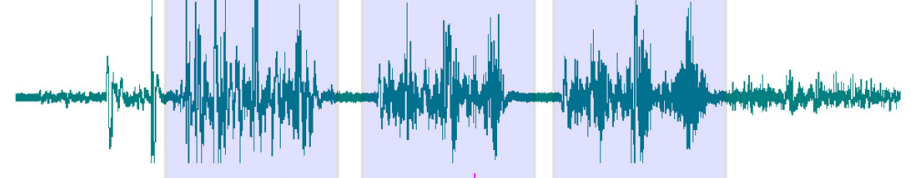

VL

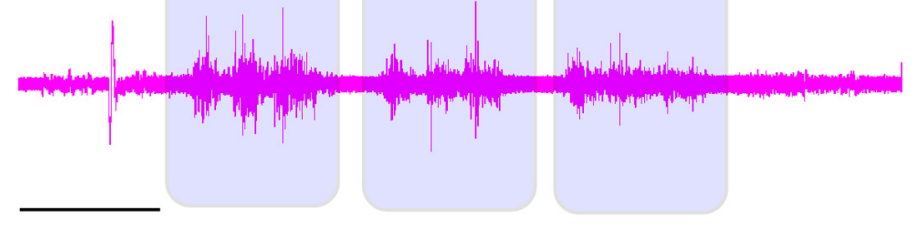

5s

Figure 6. Representative example of EMG recordings in multiple hindlimb muscles during passive joint rotations 1 month after spinal transection. Three flexion/extension cycles $(1 \mathrm{~Hz}$ with $3 \mathrm{~s}$ between each triplet) were performed at the ankle, knee, and hip joints. Rotations of the ankle evoked strong EMG responses in muscles acting at the knee and hip. Rotations of the knee and hip joint also evoke strong responses in muscles that act at the ankle joint.

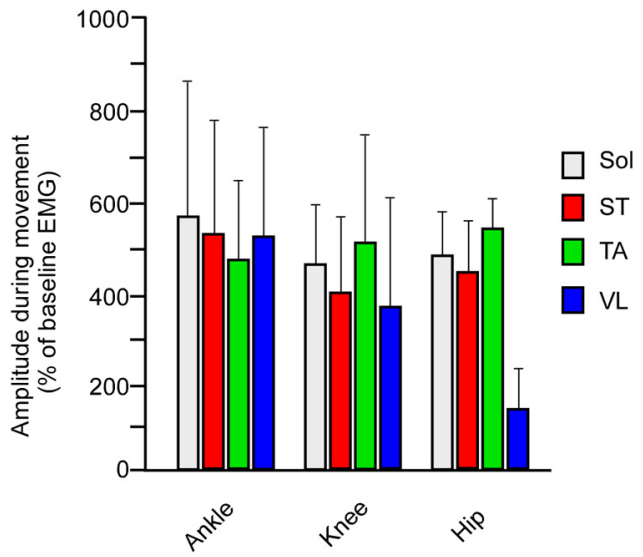

Figure 7. Percentage change in EMG activity of limb muscles during passivejoint rotations 1 month after spinal transection. EMG activity expressed as a percentage of baseline EMG. Ankle rotations produced large changes in EMG signals not only in muscles acting at the ankle joint (soleus and tibialis anterior) but also in muscles acting at the knee (vastus lateralis) and hip (semitendinosus). Rotations of the knee joint produced similarly large activations of muscles acting at the ankle and hip, and rotations of the hip produced strong responses in muscles acting at the ankle and knee.

also been shown to be present in ankle torque production in response to passive hip oscillations in humans (Onushko et al., 2011). The mechanisms underlying the emergence of these unintended responses are not fully understood, but the widened $\mathrm{MN}$ receptive fields reported here provide a powerfully explanatory potential mechanism.

Although gross locomotor function recovers in a few weeks after thoracic spinal transection in cats (Barbeau and Rossignol, 1987) and locomotion improves with treadmill training, chronic disruptions in $\mathrm{MN}$ receptive fields due to improper interneuronal sensory processing after the loss of descending neuromodulation may interfere with compensatory changes that occur after other types of injuries, such as peripheral neurectomies and incomplete spinal injuries (Goldberger, 1977; Goldberger and Murray, 1980; Martinez et al., 2011). Although various studies have considered the importance of neuromodulation in general (Croul et al., 1998; Kim et al., 1999; Nothias et al., 2005), they have focused on broad activation of the descending monoaminergic systems and their influence on movement parameters.

The pathophysiology of spinal injury involves neurodegeneration that extends proximal and distal to the initial insult (Tohda and Kuboyama, 2011) and includes inflamation, edema, and apoptosis and necrosis of the neural tissue (Mothe and Tator, 2012). This degenerative plasticity is followed shortly by restorative plasticity that includes axonal sprouting. There is considerable evidence that, after contralateral pyramidotomy, spared contralateral as well as ipsilateral corticospinal tract axons show strong outgrowth (Brus-Ramer et al., 2007). More recently, it has also been shown that segmental afferents from Ia muscle spindles show strong sprouting in as little as $10 \mathrm{~d}$ after contralateral pyramidal tract lesion. This sprouting may contribute to spastic-like behavior, as the authors demonstrated that the rate-dependent reduction of the $\mathrm{H}$-reflex was substantially reduced (Tan et al., 2012). It cannot be ruled out that the expanded receptive fields we report here are at least somewhat attributable to segmental afferent outgrowth. In contusion and other partial spinal injuries, including hemisection and staggered hemisections, plasticity is evident in axonal rerouting and axonal sprouting. But in complete spinal transection, as we have surgically induced here, sprouting and functional reconnection usually do not occur. Inhibitory molecules from central fiber myelin sheaths and glial scar formation resist axon growth and sprouting through the injury site (Kapfhammer, 1997). The ankle extensor MNs we recorded from are located several segments caudal to the transection site and are not likely the recipients of regenerated axons or axonal sprouting. Even if regeneration of descending cortical axons did occur, they would not impact $\mathrm{MN}$ or interneuron behavior during our experiments in these decerebrate animals. However, fostering the growth of descending monoaminergic axons from the brainstem as a potential source of neuromodulation for spinal circuits distal to the injury site is a focus of our future research.

MN intrinsic characteristics can change in the weeks and months after spinal injury (Cope et al., 1986), and this plasticity cannot be ruled out as a contributor to the results seen here. However, these important experiments were conducted on barbiturate-anesthetized animals, and the changes in intrinsic properties in anesthetized preparations have to now be interpreted in a new context. It has become increasingly clear that both MNs and interneurons are critically dependent on neuromodulation for proper functioning. Further, the input conductance of our MNs in the acute spinal state were not significantly different from that in the intact state (mean $1.4 \pm 0.6 \mu \mathrm{S}$ ). Conductance of our cells in the chronically injured state here (mean $1.7 \pm 0.7 \mu \mathrm{S}$ ) is on average only slightly larger than the cells from this previous study, suggesting that a significant conversion of $\mathrm{MN}$ properties has not occurred, consistent with previous studies (Hochman 
and McCrea, 1994). Moreover, conversion to fast-like motor units is unlikely a primary factor in producing expanded receptive fields, as the input conductance of our intact and acutely spinalized samples in our previous studies was not significantly different (Hyngstrom et al., 2008b). The absence of the correct neuromodulatory balance alters interneuronal processing of sensory inputs (Jordan and McCrea, 1976; Jankowska et al., 2000), which then could lead to reception of inappropriate sensory signals at spinal MNs causing unintended force production.

\section{Recovery of PICs after SCI}

PICs radically change neuron behavior by amplifying synaptic inputs and prolonging their effects (Lee and Heckman, 1996; Bennett et al., 1998; Hultborn, 2001; Hultborn et al., 2003), and PICs depend on and are controlled by monoaminergic inputs from the brainstem (Lee and Heckman, 2000). PICs and MN excitability as well as the plateau potentials and sustained activity they induce are virtually abolished immediately after spinal transection (Crone et al., 1988; Hyngstrom et al., 2008b; Frigon et al., 2011). But PICs have been shown to be present in the weeks after acute spinal transection resulting from constitutively active 5HT2 receptors in rat spinal MNs as well as in human patients with chronic spinal injuries as measured by the reduced synaptic drive needed to maintain self-sustained firing in the paired motor unit analysis technique (Gorassini et al., 2004). However, there have not as yet been any published examples chronicling the recovery of $\mathrm{MN}$ intrinsic properties from the same species under the same conditions. We show here, for the first time, a clear comparison between PIC amplitude in the uninjured state (Hyngstrom et al., 2008b) and at 1 month after spinalization in the same species. It is apparent from our data that, in as little as 5 weeks after injury, PICs have recovered $\sim 85 \%$ of their intact state amplitude as measured in previous experiments with identical controls (Hyngstrom et al., 2007, 2008b; Johnson et al., 2012).

Our previous work has shown that PIC amplitude is strongly modulated by muscle length change and therefore joint angle (Hyngstrom et al., 2007). This makes assessments of neuron intrinsic properties highly state-dependent, depending heavily on limb position. To avoid this issue, we kept the ankle angle in a neutral position and compared the PIC amplitudes in our chronic preparation with PICs in intact cord preparations with the same joint angle.

\section{Altered receptive fields and spasticity}

The term "spasticity" has long been overused and its definition seldom agreed upon. One of the most common definitions, a velocity-dependent increase in tonic stretch reflexes, is imperfect and not sufficiently inclusive. In the 1970s, Landau famously pointed out the broad array of behaviors that are commonly included under the umbrella of spasticity (Landau, 1974). For the purpose of this paper, we use the term "spasms" to describe reflex muscle activations not seen in the uninjured state.

In our previous experiments, the expanded receptive fields in ankle MNs were evident by the fact that the $\triangle \mathrm{PT}$ synaptic currents for joint rotations that elicited only small currents in the intact state became much larger after acute transection. These synaptic currents were substantial $(\sim 2-9 \mathrm{nA})$ and sufficient to depolarize all low and medium threshold (type S, FR) MNs to reach recruitment in the intact state with monoamine-mediated PICs (Powers et al., 2012). However, in the acute stage of spinal injury, even though synaptic transmission from muscle spindle afferents is potentiated (Nelson et al., 1979), MN excitability is low, so the effects of expanded MN receptive fields do not man- ifest as muscle activations; they are evident only by measuring currents directly at the $\mathrm{MN}$ soma.

It is clear from the present study that the emergence of unintended muscle activation after spinal injury involves changes in the organization of sensory synaptic inputs at MNs as well as changes in MN intrinsic properties. It is not to be ruled out that other mechanisms, such as segmental sprouting, may contribute to altered sensory inputs to the MNs as well as intrinsic changes in motor unit properties. Although we did not record directly from interneurons, changes in interneuronal pathways involved in the initial reception of movement-related sensory inputs are likely the source of this altered somatotopy. This combination of altered sensory processing by interneuronal circuits and reemergent intrinsic $\mathrm{MN}$ excitability can spread spastic behavior through the entire limb.

The inappropriately wide receptive fields of MNs after spinal injury would likely seriously distort the effects of any surviving motor commands. In incomplete spinal injury, where some descending axons are spared, volitional commands would be in competition with these aberrant sensory-evoked EPSPs.

\section{References}

Abbinanti MD, Harris-Warrick RM (2012) Serotonin modulates multiple calcium current subtypes in commissural interneurons of the neonatal mouse. J Neurophysiol 107:2212-2219. CrossRef Medline

Abbinanti MD, Zhong G, Harris-Warrick RM (2012) Postnatal emergence of serotonin-induced plateau potentials in commissural interneurons of the mouse spinal cord. J Neurophysiol 108:2191-2202. CrossRef Medline

Barbeau H, Rossignol S (1987) Recovery of locomotion after chronic spinalization in the adult cat. Brain Res 412:84-95. CrossRef Medline

Bennett DJ, Hultborn H, Fedirchuk B, Gorassini M (1998) Synaptic activation of plateaus in hindlimb motoneurons of decerebrate cats. J Neurophysiol 80:2023-2037. Medline

Bennett DJ, Li Y, Harvey PJ, Gorassini M (2001a) Evidence for plateau potentials in tail motoneurons of awake chronic spinal rats with spasticity. J Neurophysiol 86:1972-1982. Medline

Bennett DJ, Li Y, Siu M (2001b) Plateau potentials in sacrocaudal motoneurons of chronic spinal rats, recorded in vitro. J Neurophysiol 86:19551971. Medline

Binder MD, Heckman CJ, Powers RK (2002) Relative strengths and distributions of different sources of synaptic input to the motoneurone pool: implications for motor unit recruitment. Adv Exp Med Biol 508:207-212. CrossRef Medline

Bjorklund AS. (1982) Descending monoaminergic projections to the spinal cord. In: Brain stem control of spinal mechanisms, pp 55-88. Amsterdam: Elsevier.

Brus-Ramer M, Carmel JB, Chakrabarty S, Martin JH (2007) Electrical stimulation of spared corticospinal axons augments connections with ipsilateral spinal motor circuits after injury. J Neurosci 27:13793-13801. CrossRef Medline

Bui TV, Grande G, Rose PK (2008) Multiple modes of amplification of synaptic inhibition to motoneurons by persistent inward currents. J Neurophysiol 99:571-582. CrossRef Medline

Burkholder TJ, Nichols TR (2004) Three-dimensional model of the feline hindlimb. J Morphol 261:118-129. CrossRef Medline

Cope TC, Bodine SC, Fournier M, Edgerton VR (1986) Soleus motor units in chronic spinal transected cats: physiological and morphological alterations. J Neurophysiol 55:1202-1220. Medline

Crone C, Hultborn H, Kiehn O, Mazieres L, Wigström H (1988) Maintained changes in motoneuronal excitability by short-lasting synaptic inputs in the decerebrate cat. J Physiol 405:321-343. Medline

Croul S, Radzievsky A, Sverstiuk A, Murray M (1998) NK1, NMDA, 5HT1a, and 5HT2 receptor binding sites in the rat lumbar spinal cord: modulation following sciatic nerve crush. Exp Neurol 154:66-79. CrossRef Medline

Dougherty KJ, Bannatyne BA, Jankowska E, Krutki P, Maxwell DJ (2005) Membrane receptors involved in modulation of responses of spinal dorsal horn interneurons evoked by feline group II muscle afferents. J Neurosci 25:584-593. CrossRef Medline 
Fedirchuk B, Dai Y (2004) Monoamines increase the excitability of spinal neurones in the neonatal rat by hyperpolarizing the threshold for action potential production. J Physiol 557:355-361. CrossRef Medline

Frigon A, Johnson MD, Heckman CJ (2011) Altered activation patterns by triceps surae stretch reflex pathways in acute and chronic spinal cord injury. J Neurophysiol 106:1669-1678. CrossRef Medline

Goldberger ME (1977) Locomotor recovery after unilateral hindlimb deafferentation in cats. Brain Res 123:59-74. CrossRef Medline

Goldberger ME, Murray M (1980) Locomotor recovery after deafferentation of one side of the cat's trunk. Exp Neurol 67:103-117. CrossRef Medline

Gorassini MA, Knash ME, Harvey PJ, Bennett DJ, Yang JF (2004) Role of motoneurons in the generation of muscle spasms after spinal cord injury. Brain 127:2247-2258. CrossRef Medline

Hammar I, Bannatyne BA, Maxwell DJ, Edgley SA, Jankowska E (2004) The actions of monoamines and distribution of noradrenergic and serotoninergic contacts on different subpopulations of commissural interneurons in the cat spinal cord. Eur J Neurosci 19:1305-1316. CrossRef Medline

Hammar I, Stecina K, Jankowska E (2007) Differential modulation by monoamine membrane receptor agonists of reticulospinal input to lamina VIII feline spinal commissural interneurons. Eur J Neurosci 26:12051212. CrossRef Medline

Hamm TM, Turkin VV, Bandekar NK, O'Neill D, Jung R (2010) Persistent currents and discharge patterns in rat hindlimb motoneurons. J Neurophysiol 104:1566-1577. CrossRef Medline

Heckman CJ, Enoka RM (2012) Motor unit. Compr Physiol 2:2629-2682. CrossRef Medline

Heckman CJ, Lee RH, Brownstone RM (2003) Hyperexcitable dendrites in motoneurons and their neuromodulatory control during motor behavior. Trends Neurosci 26:688-695. CrossRef Medline

Heckman CJ, Hyngstrom AS, Johnson MD (2008) Active properties of motoneurone dendrites: diffuse descending neuromodulation, focused local inhibition. J Physiol 586:1225-1231. CrossRef Medline

Hochman S, McCrea DA (1994) Effects of chronic spinalization on ankle extensor motoneurons: II. Motoneuron electrical properties. J Neurophysiol 71:1468-1479. Medline

Hultborn H. (2001) State-dependent modulation of sensory feedback. J Physiol 533:5-13. CrossRef Medline

Hultborn H, Brownstone RB, Toth TI, Gossard JP (2004) Key mechanisms for setting the input-output gain across the motoneuron pool. Prog Brain Res 143:77-95. Medline

Hultborn H, Denton ME, Wienecke J, Nielsen JB (2003) Variable amplification of synaptic input to cat spinal motoneurones by dendritic persistent inward current. J Physiol 552:945-952. CrossRef Medline

Hyngstrom AS, Johnson MD, Miller JF, Heckman CJ (2007) Intrinsic electrical properties of spinal motoneurons vary with joint angle. Nat Neurosci 10:363-369. CrossRef Medline

Hyngstrom AS, Johnson MD, Heckman CJ (2008a) Summation of excitatory and inhibitory synaptic inputs by motoneurons with highly active dendrites. J Neurophysiol 99:1643-1652. CrossRef Medline

Hyngstrom A, Johnson M, Schuster J, Heckman CJ (2008b) Movementrelated receptive fields of spinal motoneurones with active dendrites. J Physiol 586:1581-1593. CrossRef Medline

Jankowska E, Hammar I, Chojnicka B, Hedén CH (2000) Effects of monoamines on interneurons in four spinal reflex pathways from group I and/or group II muscle afferents. Eur J Neurosci 12:701-714. CrossRef Medline

Johnson MD, Hyngstrom AS, Manuel M, Heckman CJ (2012) Push-pull control of motor output. J Neurosci 32:4592-4599. CrossRef Medline

Jordan LM, McCrea DA (1976) Analysis of the effects of p-methoxyphenylethylamine on spinal cord neurones. Br J Pharmacol 57:191-199. CrossRef Medline

Kapfhammer JP (1997) Axon sprouting in the spinal cord: growth promoting and growth inhibitory mechanisms. Anat Embryol (Berl) 196:417426. CrossRef Medline

Kim D, Adipudi V, Shibayama M, Giszter S, Tessler A, Murray M, Simansky KJ (1999) Direct agonists for serotonin receptors enhance locomotor function in rats that received neural transplants after neonatal spinal transection. J Neurosci 19:6213-6224. Medline

Krawitz S, Fedirchuk B, Dai Y, Jordan LM, McCrea DA (2001) Statedependent hyperpolarization of voltage threshold enhances motoneu- rone excitability during fictive locomotion in the cat. J Physiol 532:271281. CrossRef Medline

Landau WM (1974) Spasticity: the fable of a neurological demon and the emperor's new therapy [Editorial]. Arch Neurol 31:217-219. CrossRef Medline

Lee RH, Heckman CJ (1996) Influence of voltage-sensitive dendritic conductances on bistable firing and effective synaptic current in cat spinal motoneurons in vivo. J Neurophysiol 76:2107-2110. Medline

Lee RH, Heckman CJ (1998) Bistability in spinal motoneurons in vivo: systematic variations in persistent inward currents. J Neurophysiol 80:583593. Medline

Lee RH, Heckman CJ (2000) Adjustable amplification of synaptic input in the dendrites of spinal motoneurons in vivo. J Neurosci 20:6734-6740. Medline

Martinez M, Delivet-Mongrain H, Leblond H, Rossignol S (2011) Recovery of hindlimb locomotion after incomplete spinal cord injury in the cat involves spontaneous compensatory changes within the spinal locomotor circuitry. J Neurophysiol 106:1969-1984. CrossRef Medline

Maxwell DJ, Riddell JS, Jankowska E (2000) Serotoninergic and noradrenergic axonal contacts associated with premotor interneurons in spinal pathways from group II muscle afferents. Eur J Neurosci 12:1271-1280. CrossRef Medline

Mendell LM (1966) Physiological properties of unmyelinated fiber projection to the spinal cord. Exp Neurol 16:316-332. CrossRef Medline

Mothe AJ, Tator CH (2012) Advances in stem cell therapy for spinal cord injury. J Clin Invest 122:3824-3834. CrossRef Medline

Murray KC, Nakae A, Stephens MJ, Rank M, D’Amico J, Harvey PJ, Li X, Harris RL, Ballou EW, Anelli R, Heckman CJ, Mashimo T, Vavrek R, Sanelli L, Gorassini MA, Bennett DJ, Fouad K (2010) Recovery of motoneuron and locomotor function after spinal cord injury depends on constitutive activity in 5-HT2C receptors. Nat Med 16:694-700. CrossRef Medline

Nelson SG, Collatos TC, Niechaj A, Mendell LM (1979) Immediate increase in Ia-motoneuron synaptic transmission caudal to spinal cord transection. J Neurophysiol 42:655-664. Medline

Nothias JM, Mitsui T, Shumsky JS, Fischer I, Antonacci MD, Murray M (2005) Combined effects of neurotrophin secreting transplants, exercise, and serotonergic drug challenge improve function in spinal rats. Neurorehabil Neural Repair 19:296-312. CrossRef Medline

Onushko T, Hyngstrom A, Schmit BD (2011) Bilateral oscillatory hip movements induce windup of multijoint lower extremity spastic reflexes in chronic spinal cord injury. J Neurophysiol 106:1652-1661. CrossRef Medline

Powers RK, Binder MD (2001) Input-output functions of mammalian motoneurons. Rev Physiol Biochem Pharmacol 143:137-263. CrossRef Medline

Powers RK, Elbasiouny SM, Rymer WZ, Heckman CJ (2012) Contribution of intrinsic properties and synaptic inputs to motoneuron discharge patterns: a simulation study. J Neurophysiol 107:808-823. CrossRef Medline

Rank MM, Murray KC, Stephens MJ, D’Amico J, Gorassini MA, Bennett DJ (2011) Adrenergic receptors modulate motoneuron excitability, sensory synaptic transmission and muscle spasms after chronic spinal cord injury. J Neurophysiol 105:410-422. CrossRef Medline

Rekling JC, Funk GD, Bayliss DA, Dong XW, Feldman JL (2000) Synaptic control of motoneuronal excitability. Physiol Rev 80:767-852. Medline

Silverman J, Garnett NL, Giszter SF, Heckman CJ 2nd, Kulpa-Eddy JA, Lemay MA, Perry CK, Pinter M (2005) Decerebrate mammalian preparations: unalleviated or fully alleviated pain? A review and opinion. Contemp Top Lab Anim Sci 44:34-36. Medline

Tan AM, Chakrabarty S, Kimura H, Martin JH (2012) Selective corticospinal tract injury in the rat induces primary afferent fiber sprouting in the spinal cord and hyperreflexia. J Neurosci 32:12896-12908. CrossRef Medline

Tohda C, Kuboyama T (2011) Current and future therapeutic strategies for functional repair of spinal cord injury. Pharmacol Ther 132:57-71. CrossRef Medline

Wang D, Grillner S, Wallén P (2011) 5-HT and dopamine modulates $\mathrm{CaV} 1.3$ calcium channels involved in postinhibitory rebound in the spinal network for locomotion in lamprey. J Neurophysiol 105:1212-1224. CrossRef Medline 